\title{
Minimally invasive surgery for gastric cancer - toward a confluence of two major streams: a review
}

\author{
Yuko Kitagawa ${ }^{1}$, Seigo Kitano ${ }^{2}$, Tetsuro Kubota ${ }^{1}$, Koichiro Kumai $^{1}$, Yoshihide Otani ${ }^{1}$, Yoshiro Saikawa ${ }^{1}$, \\ MASASHI Yoshida ${ }^{1}$, and MasaKi KitaJima ${ }^{1}$ \\ ${ }^{1}$ Department of Surgery, Keio University School of Medicine, 35 Shinanomachi, Shinjuku-ku, Tokyo 160-8582, Japan \\ ${ }^{2}$ Department of Surgery, Oita University, Faculty of Medicine, Oita, Japan
}

\begin{abstract}
The minimalization of therapeutic invasiveness in order to preserve quality of life (QOL) is a major topic in the management of early gastric cancer. After laparoscopic surgery for gastric cancer was introduced by Kitano et al. in 1991, an enthusiasm to develop laparoscopic procedures has grown steadily. In the initial phase, early gastric cancer limited to the mucosal layer with no risk of lymph node metastasis was treated by laparoscopic wedge resection or intragastric mucosal resection. Since technical and instrumental advances in endoscopic treatment were achieved by gastroenterologists, these cases can be managed by intraluminal endoscopic approaches. The attention of surgeons then shifted to more radical procedures such as laparoscopic gastrectomy with lymph node dissection, which is comparable to open surgery and can be indicated even in advanced cancer. Although this paradigm shift has already been realized in the field of colorectal surgery, we must pay attention to the particular biological nature of gastric cancer in terms of the potential of peritoneal dissemination. While early-phase recovery after surgery has been improved by laparoscopic surgery, preservation of late-phase QOL by function-preserving surgery is also essential in this regard; therefore, the sentinel node $(\mathrm{SN})$ concept has been a much-discussed topic in gastric cancer surgery to approach this aspect. Recently, the validity of the SN concept has been demonstrated by a number of single institutional studies, and prospective multicenter trials are currently ongoing. Theoretically, various types of function-preserving surgery could be applied in cases of early gastric cancer with negative SNs as less invasive surgery to improve long-term QOL. Although we still have to solve several remaining issues in the treatment of gastric cancers, a confluence of these two major streams, laparoscopic surgery and sentinel node navigation surgery, would enable us to apply a novel individualized minimally invasive approach, both in terms of degree of incisional access and extent of function preservation.
\end{abstract}

Offprint requests to: Y. Kitagawa

Received: February 10, 2005 / Accepted: February 23, 2005
Key words Minimally invasive surgery - Laparoscopic surgery $\cdot$ Sentinel node $\cdot$ Gastric cancer $\cdot$ Micrometastasis

\section{Introduction}

The history of laparoscopic surgery for gastric cancer began with the reports of successful laparoscopic distal gastrectomy performed successfully by Kitano in 1991, only a few years after the introduction of laparoscopic cholecystectomy [1]. Laparoscopic surgery appeared as an intermediate option between endoscopic mucosal resection (EMR) and conventional open gastrectomy. In the initial phase, the indications were strictly limited to mucosal gastric cancer with no risk of lymph node involvement. Laparoscopic local resection procedures for these cases were reported by pioneers in the early 1990s [2,3]. Owing to the technical advances in EMR, the indications of laparoscopic local resection for mucosal gastric cancer have gradually decreased. On the other hand, technical and instrumental developments in laparoscopic surgery have allowed more aggressive surgery for gastric cancer with lymph node dissection. Several single institutional studies demonstrated that laparoscopy-assisted distal gastrectomy (LADG) caused less pain and enabled faster recovery and shorter hospital stay, which are parameters of early-phase quality of life (QOL). However, levels of organ function and QOL in the late phase after laparoscopy-assisted gastrectomy should ideally be identical to those of conventional open surgery. From the late 1990s, attempts to solve this issue by individualized function-preserving surgery based on regional lymph node status have focused on the sentinel node (SN) concept as another tributary to the stream of minimally invasive surgery for gastric cancer. Now we must pay attention to both minimal invasiveness for early-phase recovery as well as achieving satisfactory late-phase function after gastric 


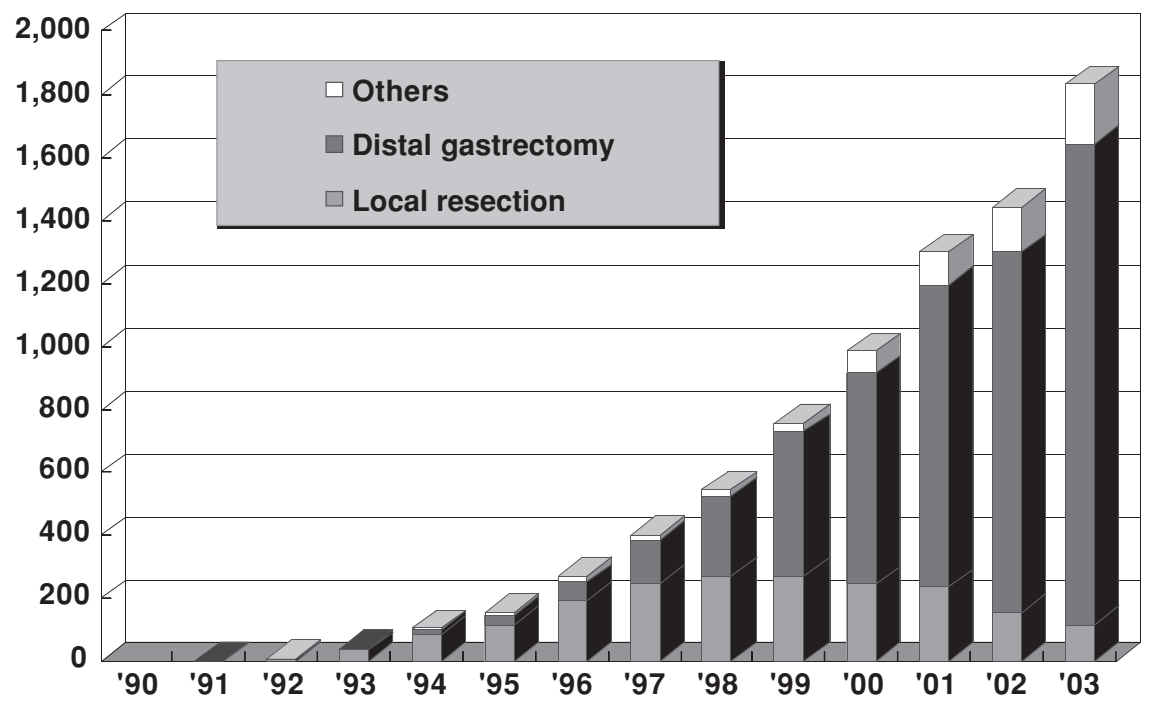

Fig. 1. Nationwide survey of laparoscopic surgery for gastric cancer, 2004. The total number of cases treated by LADG has increased sharply, while the number of cases treated by laparoscopic local resection (LWR and IGMR) has remained unchanged in recent years cancer surgery. Here we would like to review the past and current status of these two major streams of minimally invasive surgery for gastric cancer and discuss the future direction of this field.

\section{Initial challenges in laparoscopic surgery for gastric cancer}

Ohgami and colleagues first developed laparoscopic wedge resection (LWR) of the stomach using a lesionlifting method [2]. This procedure enables complete local resection with full thickness of the stomach wall and organ preservation by a laparoscopic approach. The indications of this procedure were initially strictly limited to early gastric mucosal cancer with no risk of lymph node involvement. Intragastric mucosal resection (IGMR) developed by Ohashi also enabled a wide range of mucosal resections of lesions located in any part of the stomach except the anterior wall [3]. Although there has been no randomized prospective study to confirm the clinical advantages of these laparoscopic procedures, a survey of the Japan Society for Endoscopic Surgery (JSES) showed limited morbidity (intraoperative: LWR 2.1\%, IGMR 4.2\%; postoperative: LWR 4.2\%, IGMR 6.5\%) and no mortality [4,5]. Faster recovery and early discharge from hospital were demonstrated by the survey [4]. The low incidence of local recurrence after LWR and its manageability were also reported [6]. LWR and IGMR have become well accepted as minimally invasive procedures for mucosal gastric cancer since they began to be performed in the early 1990s.

\section{Current trends of laparoscopic gastric cancer surgery}

The 2004 national survey conducted by JSES demonstrated that about 7800 patients with gastric cancer underwent laparoscopic surgery from 1991 to 2003 (Fig. 1) [7]. In 2003 LADG, LWR, and IGMR accounted for $83 \%, 5 \%$, and $1.5 \%$ of cases, respectively. The number of instances of LADG has increased rapidly since 1996. Despite the clinical merits of LWR and IGMR, the mode of procedure has been shifted from laparoscopic local resection to laparoscopy-assisted gastrectomy with lymph node dissection, as shown in Fig. 1, mainly because of two reasons. (1) Recent advances in EMR technology, including development of endoscopic submucosal dissection (ESD), have improved local control of mucosal gastric cancer for which laparoscopic local resection was previously indicated [8,9]. (2) Technical and instrumental laparoscopic advances in lymph node dissection enable curative gastrectomy even in cases with potential lymph node involvement [10-12].

Although LWR and IGMR can be technically applicable for submucosal gastric cancer, the limited reliability of preoperative diagnosis of lymph node metastasis in these cases is an obstacle to these applications [13].

\section{Clinical benefits of laparoscopy-assisted gastrectomy for gastric cancer}

Compared with conventional open surgery, laparoscopic gastrectomy is reported to have several benefits for patients, including less pain, less inflammatory response, faster recovery of gastrointestinal function, 
Table 1. Advantages and disadvantages of laparoscopyassisted distal gastrectomy in comparison with conventional open surgery

Advantages
Cosmetic benefits
Less pain
Reduced inflammatory response
Faster recovery of bowel function
Less blood loss
Better pulmonary function
Shorter hospital stay
Preserved immune-function
Cost/benefit?
Disadvantages
Complicated procedure
Longer operation time
Cost/benefit?

preserved postoperative immune function, shorter hospital stay, reduced medical costs, and better QOL [14-22] (Table 1). Kitano and colleagues conducted a single institutional prospective randomized study and described several advantages including less pain and better pulmonary function after LADG in comparison with open surgery [23]. Recently Huscher et al. reported the 5-year postoperative results of a prospective randomized clinical trial of laparoscopic versus open subtotal gastrectomy for distal gastric cancer in a total of 59 patients [24]. There is no significant difference in mean number of resected lymph nodes, operative morbidity and mortality, and 5-year overall and disease-free survival between these two groups. Reduced blood loss, shorter time to resumption of oral intake, and earlier discharge from hospital are described in this report as additional benefits of laparoscopic gastrectomy. A large-scale multicenter randomized controlled trial is required to confirm the clinical benefits of LADG. The relatively longer operation time than conventional surgery requires and uncertainty concerning cost benefits are still debated issues.

\section{What are the limits to the indications of laparoscopic gastrectomy?}

In March 2001, the Japanese Gastric Cancer Association proposed clinical guidelines for the treatment of gastric cancer in Japan and revised them in 2004 [25,26]. While LADG was recommended for mucosal cancers with limited lymph node metastasis (N1) and submucosal cancers with no or limited lymph node metastasis (N0, N1) in these guidelines, LADG was also described as a practice still under clinical investigation because of the uncertain quality of lymph node dissection and long- term results. Although skilled laparoscopic surgeons demonstrated that complete laparoscopic gastrectomy and D2 lymphadenectomy were technically feasible even in advanced gastric cancer [27], the indications of LADG vary among institutes from cT1N0 to cT2N1 [28]. The extent of lymph node dissection performed with LADG also varies among institutes, from D0 to D2 [28]. Hand-assisted technique is reported as a bridge learning technique to experience laparoscopic surgery [29]. There is a significant learning curve and an entire experienced surgical team including assistants and laparoscopists is required to achieve a stable procedure. Although more complicated laparoscopic procedures such as total gastrectomy and proximal gastrectomy are also technically feasible for experienced surgeons $[30,31]$, these procedures are still not routine in community hospitals.

In colon cancer, advantages of laparoscopic surgery in the early phase after surgery and no impairment of the quality of surgery with regard to long-term survival have been demonstrated [32-34]. Although evaluation of overall cost benefits in laparoscopic colorectal surgery is still controversial $[35,36]$, a major group of laparoscopic colorectal surgeons is oriented to more extensive procedures for more advanced cases. In gastric cancer, however, we must consider the biological behavior of the disease entity including a relatively high risk of peritoneal dissemination, which might be promoted by laparoscopic procedures [37,38]. Recently Hirabayashi et al. demonstrated that cell adhesion molecules integrin and CD44 play an important role in the development of port-site metastasis after laparoscopic surgery and proposed preventive effects through modulation of these molecules [39]. For the further development of laparoscopic gastric cancer surgery, preclinical and oncological research is crucial, in addition to evaluation of the quality control of the procedures.

\section{Function-preserving surgery for gastric cancer: another type of minimally invasive surgery}

While early-phase QOL can be improved by laparoscopic surgery, late-phase QOL is more difficult to evaluate as it is closely related to organ and function preservation after surgery. Function-preserving surgery with limited resection extent and modified lymph node dissection has been investigated. In terms of organ preservation, procedures including partial gastrectomy [40], segmental gastrectomy [41], pylorus-preserving distal gastrectomy [42], and proximal gastrectomy [43] should be considered as minimally invasive approaches no matter whether we perform them via laparotomy or laparoscopic surgery. Pylorus-preserving distal gastrectomy and segmental gastrectomy have been reported to 
Table 2. Single institutional results of SN mapping for gastric cancer [45-63]

\begin{tabular}{|c|c|c|c|c|c|c|}
\hline Author & Year & Journal & Method & $n$ & Detection rate & Sensitivity \\
\hline Kitagawa Y et al. & 2000 & Surg Clin N Am & RI & 36 & $97 \%$ & $100 \%$ \\
\hline Hiratsuka $\mathrm{M}$ et al. & 2001 & Surgery & Dye & 77 & $99 \%$ & $90 \%$ \\
\hline Yasuda S et al. & 2001 & Tokai J Exp Clin Med & RI & 26 & $100 \%$ & $82 \%$ \\
\hline Ichikura T et al. & 2002 & World J Surg & Dye & 62 & $100 \%$ & $85 \%$ \\
\hline Kitagawa Y et al. & 2002 & Br J Surg & RI & 145 & $95 \%$ & $92 \%$ \\
\hline Carlini $\mathrm{M}$ et al. & 2002 & $J$ Exp Clin Cancer Res & Dye & 40 & $100 \%$ & $87 \%$ \\
\hline Hayashi $\mathrm{H}$ et al. & 2003 & J Am Coll Surg & RI+Dye & 31 & $100 \%$ & $100 \%$ \\
\hline Miwa K et al. & 2003 & Br J Surg & Dye & 211 & $96.2 \%$ & $89 \%$ \\
\hline Gretschel S et al. & 2003 & Chirurg & RI & 15 & $93 \%$ & $89 \%$ \\
\hline Yasuda S et al. & 2003 & Jpn J Clin Oncol & RI & 21 & $100 \%$ & $100 \%$ \\
\hline Tonouchi $\mathrm{H}$ et al. & 2003 & Dig Surg & $\mathrm{RI}+$ Dye & 17 & $100 \%$ & $100 \%$ \\
\hline Simsa J et al. & 2003 & Acta Chir Belg & Dye & 22 & $100 \%$ & $56 \%$ \\
\hline Ryu KW et al. & 2003 & Eur J Surg Oncol & Dye & 71 & $92 \%$ & $100 \%$ \\
\hline Song $\mathrm{X}$ et al. & 2004 & Am J Surg & Dye & 27 & $96 \%$ & $100 \%$ \\
\hline Kim MC et al. & 2003 & Hepatogastroenterology & RI & 22 & $91 \%$ & $82.2 \%$ \\
\hline Nimura $\mathrm{H}$ et al. & 2004 & Br J Surg & Dye & 84 & $99 \%$ & $100 \%$ \\
\hline Karube T et al. & 2004 & $J$ Surg Oncol & RI+Dye & 41 & $100 \%$ & $92 \%$ \\
\hline Kim MC et al. & 2004 & Ann Surg & RI & 46 & $93.5 \%$ & $84.6 \%$ \\
\hline Osaka H et al. & 2004 & Clin Cancer Res & Dye & 57 & $100 \%$ & $100 \%$ \\
\hline
\end{tabular}

RI, radioisotope-labeled colloid guided method; Dye, dye-guided method

have less frequent dumping syndrome than conventional Billroth I gastrectomy [41,42]. Although limited lymph node dissection and autonomic nerve preservation will help improve functional results after gastric cancer surgery, a certain incidence of skip metastasis in the second or third compartment of regional lymph nodes is an obstacle to the wider introduction of this procedure. As a means to overcome this issue, the sentinel node ( $\mathrm{SN}$ ) concept has attracted attention in recent years and is anticipated to become a novel diagnostic tool for identification of clinically undetectable lymph node metastasis in patients with early gastric cancer.

\section{Introduction of the sentinel node concept in gastric cancer surgery}

The first possible sites of metastasis along the route of lymphatic drainage from the primary lesion are known as sentinel nodes (SNs), and these are detectable using injection of either dyes or radioactive tracers, or both. Since Morton et al. demonstrated the concept of SN initially in a feline model, and later in a clinical study involving patients with malignant melanoma [44], the clinical impact of the SN concept has become a major topic with regard to various solid tumors. Until the late 1990s, the application of the SN concept to gastrointestinal (GI) malignancies met resistance because of the multidirectional and complicated lymphatic flow from the GI tract and the relatively high incidence of ana- tomical skip metastases. In gastric cancer, this clinical evidence supported the validity of D2 lymph node dissection, even for clinically negative node cases.

In the past 5 years, a number of single institutional studies supporting the validity of the SN concept for GI cancers have been reported (Table 2) [45-63]. Despite initial skepticism of experienced GI surgeons concerning this concept in the management of gastric cancer, recent reports support its validity. Unexpected anatomical skip metastases might be accounted for by aberrant drainage routes from primary lesion. Reports indicate that $5 \%-10 \%$ of SNs in cases of gastric cancer are located in the second compartment and not in the perigastric nodes, i.e., the first compartment. Our experience with $\mathrm{SN}$ mapping identifying such cases leads us to believe that this technique has great value in identifying these aberrant lymphatic drainage routes in individual patients.

The most common cause for a false negative result of $\mathrm{SN}$ mapping in gastric cancer is a lymphatic vessel obstructed by cancer invasion. In these cases, the administered tracer cannot migrate into the real SNs, and its flow will take the path of least resistance, leading it to the second-echelon, or false, SNs. Clinically positive node cases and cases with advanced tumor are not indications for SN mapping for this reason. The most important message from our experience in the recent 5 years is that SN mapping is useful to find clinically undetectable micrometastasis in cT1N0 gastric cancer and that it may change the overall therapeutic approach to this entity. 


\section{Multicenter prospective validation study of the SN concept in gastric cancer}

Several types of dye and radioactive colloids are used as tracers to detect $\mathrm{SN}$ in gastric cancer in the case of various other solid tumors, and consensus has yet to be reached concerning various aspects of the actual procedures, such as the type of dye and colloid, the injection routes (submucosal or subserosal), tracer volume, and observation timing. As with SN mapping of other organs, we must confirm the reliability of the procedure by multicenter prospective clinical trials before the introduction of this technology to actual patient care for gastric cancer. Isozaki and colleagues reported the results of a regional multicenter clinical trial of SN mapping for gastric cancer using the conventional dyeguided method [64]. Although the patient population enrolled in that study was limited, this first multicenter trial of SN mapping for gastric cancer provides several important messages. This study was designed to investigate the feasibility of SN mapping for gastric cancer using the dye-guided method as a simple method that can be conducted even in community hospitals without special equipment. Although the false negative rate reported in the study (29\% in T1, 44\% in T2) appears disappointing, we must take some extenuating circumstances into account when interpreting the data. The most serious limitations of this study were the inclusion criteria for the participating institutes in terms of prior experience with SN mapping for gastric cancer. In the field of breast cancer surgery, the significance of the technical learning curve for the technique has already been clearly demonstrated. Cox et al. suggested that a 30 -case experience with a detection rate of $90 \%$ or more is a minimal requirement for institutes to participate in a multicenter study of SN mapping for breast cancer [65]. In the study conducted by Isozaki et al., the learning phase for the procedure had not been completed by most of the participating institutes. Therefore, the relatively high false negative rates demonstrated in this study may be attributed to lack of technical expertise in the initial learning phase. Despite this study design limitation, false negative rates for patients with $\mathrm{T} 1$ and sN0 $(11 \%)$ were similar to those of previous singleinstitutional reports, lending support to the idea that dye-guided SN mapping may be feasible for $\mathrm{T} 1 \mathrm{sN} 0$ patients after the establishment of a standard procedure and the completion of the learning phase, at least with open surgery.

Recently a poorly designed multicenter prospective trial of SN mapping for colorectal cancer was published with disappointing results [66] (false negative rate: $54 \%$ ). It is clear that the inappropriate inclusion criteria, which allowed inclusion of patients with advanced tumors, in addition to technical errors in the initial learning phase in participating institutes with limited experience, may well have caused this discouraging result. Fortunately, two major, well-designed largescale clinical trials of SN mapping for gastric cancer for open surgery have been initiated in Japan. The Gastric Cancer Surgical Study Group of the Japan Clinical Oncology Group (JCOG) organized a multicenter prospective study of SN mapping by the dye-guided method using subserosal injection of indocyanine green. A study group in the Japan Society of Sentinel Node Navigation Surgery (SNNS) is also conducting a multicenter prospective trial of SN mapping by a dual tracer method with blue dye and radioactive colloid. The results of these clinical trials should provide perspectives on the future direction of $\mathrm{SN}$ navigation surgery for gastric cancer. If the JCOG study reveals favorable results in terms of false negative rates, the dye-guided method will be utilized as a routine practice for open surgery in a wide range of institutes. If not, we will need to consider introduction of a radio-guided method or add further technical improvements, even for open surgery. Even if the SNNS study demonstrates acceptable detection rates and low false negative rates, we need to conduct a feasibility study of laparoscopic SN mapping for gastric cancer as the next step.

\section{Current clinical applications of the sentinel node concept for gastric cancer}

Before actual validation of the SN concept by welldesigned large-scale multicenter prospective trials, it may be early to apply less-invasive operative approaches without conventional lymph node dissection for cases with a potential risk of micrometastasis in regional lymph nodes. The concept of a "sentinel lymphatic basin," proposed by Miwa [52], can provide us with an acceptable "safety net" for clinical application during this transitional phase. Prior reports have demonstrated that sentinel lymphatic basins contained truly positive nodes, even in the cases with a false negative SN biopsy. Therefore, the sentinel lymphatic basins are good targets for focused lymph node dissections for cT1N0 gastric cancer. The distribution of sentinel lymphatic basins and the status of SNs would be useful information to decide on the extent of gastric resection. Appropriate indications for proximal gastrectomy, segmental gastrectomy, pylorus-preserving gastrectomy, and partial resection for cT1N0 gastric cancer could be individually determined based on this concept. The extent of resection and lymph node dissection for carcinoma of the esophagogastric (EG) junction can be decided by location and the status of SNs [67]. These approaches have attracted the interest of Western institutes where the incidence of adenocarcinoma of the EG 


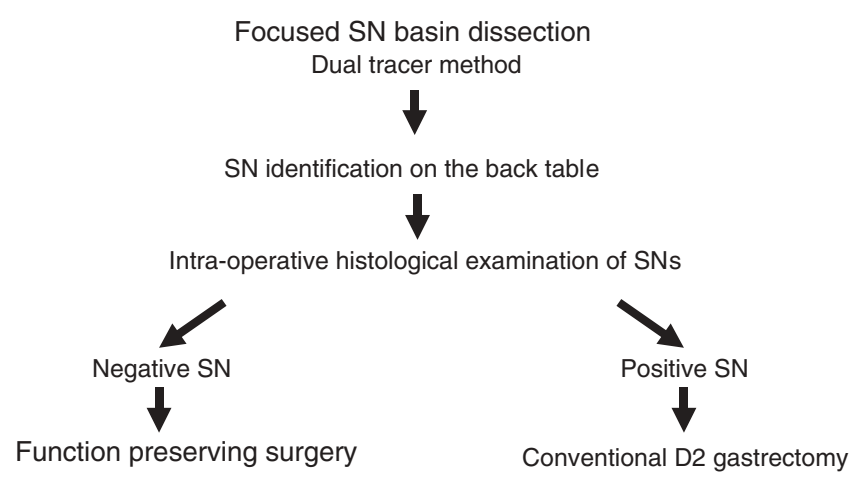

Pylorus preserving distal gastrectomy

Segmental resection

Partial resection

Limited proximal gastrectomy

Fig. 2. Current individualized strategy for early gastric cancer based on sentinel-node $(S N)$ navigation

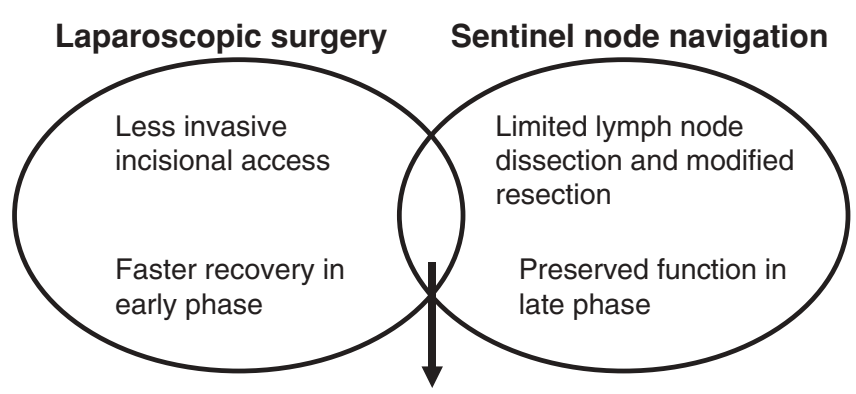

Individualized minimally invasive surgery

Fig. 3. Confluence of two major streams of minimally invasive surgery for gastric cancer

junction is increasing. These variations of tailored surgery are already feasible in open surgery. Our current strategy for early gastric cancer using SN navigation during this transitional phase is summarized in Fig. 2 [68].

\section{Laparoscopic sentinel node navigation surgery: a confluence of two major streams}

Theoretically, earlier recovery after surgery and preservation of QOL in the late phase can be achieved by laparoscopic SN navigation surgery, as shown in Fig. 3. We have introduced laparoscopic pylorus-preserving gastrectomy combined with SN mapping as individualized minimally invasive laparoscopic surgery [69]. In this procedure, the indications of pylorus preservation will be determined by the distribution and status of SNs.
In the near future, laparoscopic wedge resection for SN negative superficial gastric cancer will be feasible as minimally invasive surgery. Recently reduced indication of LWR could be expanded to SN negative submucosal gastric cancer.

A combination of EMR or ESD and SN mapping for superficial gastric cancer is another attractive challenge as a less-invasive approach. At this moment, we do not have data on the reliability of SN mapping for the cases with scars after EMR/ESD. Laparoscopic SN mapping and consequent intraoperative EMR/ESD for $\mathrm{SN}$ negative cases is likely to soon become an accepted approach. To realize these future clinical applications, there are several remaining issues that require solution.

Laparoscopic SN mapping is still under development owing to various technical and material limitations [70]. Currently available rigid-type laparoscopic gamma probes are fixed by the entry-trocar, thus freedom to search for SN, and to avoid a "shine through" effect from the injection site, is seriously restricted. At present, laparoscopic SN detection is feasible for cases with lesions on the greater curvature of the middle or lower part of the stomach. In cases of carcinoma at the EG junction, a flexible type of gamma probe is required for accurate sampling of SNs.

The clinical significance of micrometastasis and isolated tumor cells in regional lymph nodes with gastric cancer is still controversial. Unlike multimodal options for preventing axillary lymph node recurrence in breast cancer, it is difficult to control lymph node recurrence in patients with gastric cancer. It is essential to deal with micrometastasis and isolated tumor cells in SNs in patients with gastric cancer. The sensitivity of intraoperative histological examination of SN is still unsatisfactory [71]. Although the issue of a false positive study is still controversial, intraoperative utilization of real time reverse transcriptase polymerase chain reaction (RTPCR) to detect molecular metastasis might well be a useful technology for safer clinical application of the $\mathrm{SN}$ concept in GI cancer. We must clear up these unresolved issues very carefully as we proceed.

\section{Conclusions}

For early-stage gastric cancer in which generally better prognosis was achieved by conventional surgical approaches, an individualized minimally invasive surgery should be established as the next surgical challenge of the twenty-first century. A combination of laparoscopic surgery with $\mathrm{SN}$ navigation surgery has the potential to achieve this goal.

Acknowledgment The authors are indebted to Prof. J. Patrick Barron of the International Medical Com- 
munications Center of Tokyo Medical University for his review of this manuscript.

\section{References}

1. Kitano S, Iso Y, Moriyama M, Sugimachi K. Laparoscopyassisted Billroth I gastrectomy. Surg Laparosc Endosc 1994;4: 146-8.

2. Ohgami M, Kumai K, Otani Y, Kubota T, Kitajima M. Laparoscopic wedge resection of the stomach for early gastric cancer using a lesion-lifting method. Dig Surg 1994;11:64-7.

3. Ohashi S. Laparoscopic intraluminal (intragastric) surgery for early gastric cancer. Surg Endosc 1995;9:169-71.

4. Kitano S, Shiraishi N. Current status of laparoscopic gastrectomy for cancer in Japan. Surg Endosc 2004;18:182-5.

5. Kitano S, Bandoh T, Kawano K. Endoscopic surgery in Japan. Min Invas Ther \& Allied Technol 2001;10:215-9.

6. Ohgami M, Otani Y, Kumai K, Kubota T, Kim YI, Kitajima M. Curative laparoscopic surgery for early gastric cancer: five years experience. World J Surg 1999;23:187-92.

7. Japan Society for Endoscopic Surgery. Nationwide survey on endoscopic surgery in Japan. J Jpn Soc Endosc Surg 2004;9:475-569 (in Japanese).

8. Rembacken BJ, Gotoda T, Fujii T, Axon ATR. Endoscopic mucosal resection (review). Endoscopy 2001;33:709-18.

9. Ono H, Kondo H, Gotoda T, Shirao K, Saito D, Hosokawa K, et al. Endoscopic mucosal resection for treatment of early gastric cancer. Gut 2001;48:225-229.

10. Watson DI, Devitt PG, Game PA. Laparoscopic Billroth II gastrectomy for early gastric cancer. Br J Surg 1995;82:661-2.

11. Taniguchi S, Koga K, Ibusuki K, Sugio K, Uchimura Y. Laparoscopic pylorus-preserving gastrectomy with intracorporeal hand-sewn anastomosis. Surg Endosc Laparosc 1997;7:354-6.

12. Goh PM, Khan AZ, So JB, Lomanto D, Cheah WK, Muthiah R, et al. Early experience with laparoscopic radical gastrectomy for advanced gastric cancer. Surg Laparosc Endosc Percutan Tech 2001;4:98-102.

13. Nakamura K, Morisaki T, Noshiro H, Torata N, Kinukawa N, Tanaka M. Morphometric analysis of regional lymph nodes with and without metastasis from early gastric carcinoma. Cancer 2000; 88:2438-42.

14. Adachi Y, Shiraishi N, Kitano S. Modern treatment of early gastric cancer: Review of the Japanese experience. Dig Surg 2002; 19:333-9.

15. Adachi Y, Shiraishi N, Shiromizu A, Bandoh T, Aramaki M, Kitano S. Laparoscopy-assisted Billroth I gastrectomy compared with conventional open gastrectomy. Arch Surg 2000;135:806-10.

16. Adachi Y, Suematsu T, Shiraishi N, Katsuta T, Morimoto A, Kitano S, et al. Quality of life after laparoscopy-assisted Billroth I gastrectomy. Ann Surg 1999;229:49-54.

17. Shimizu S, Uchiyama A, Mizumoto K, Morisaki T, Nakamura K, Shimura $\mathrm{H}$, et al. Laparoscopically assisted distal gastrectomy for early gastric cancer. Surg Endosc 2000;14:27-31.

18. Asao T, Hosouchi Y, Nakabayashi T, Haga N, Mochiki E, Kuwano H. Laparoscopically assisted total or distal gastrectomy with lymph node dissection for early gastric cancer. Br J Surg 2001;88:128-32.

19. Migoh S, Hasuda K, Nakashima K, Anai H. The benefit of laparoscopy-assisted distal gastrectomy compared with conventional open distal gastrectomy: a case-matched control study. Hepatogastroenterology 2003;50:2241-54.

20. Mochiki E, Nakabayashi T, Kamimura H, Haga N, Asao T, Kuwano H. Gastrointestinal recovery and outcome after laparoscopy-assisted versus conventional open distal gastrectomy for early gastric cancer. World J Surg 2002;26:45-9.

21. Weber KJ, Reyes CD, Gagner M, Divino CM. Comparison of laparoscopic and open gastrectomy for malignant disease. Surg Endosc. 2003;17:968-71.
22. Fujii K, Sonoda K, Izumi K. T lymphocyte subsets and Th1/Th2 balance after laparoscopy-assisted distal gastrectomy. Surg Endosc 2003;9:1440-4.

23. Kitano S, Shiraishi N, Fujii K, Yasuda K, Inomata M, Adachi Y. A randomized controlled trial comparing an open versus a laparoscopy-assisted distal gastrectomy for the treatment of early gastric cancer: an interim report. Surgery 2002;131:S30611.

24. Huscher CG, Mingoli A, Sgarzini G, Sansonetti A, Lirici MM, Napolitano C, et al. Laparoscopic versus open subtotal gastrectomy for distal gastric cancer: five-year results of randomized prospective trial. Ann Surg 2005;241:232-7.

25. The Japanese Gastric Cancer Association. Guidelines for the treatment of gastric cancer. Tokyo: Kanehara; 2001.

26. The Japanese Gastric Cancer Association. Guidelines for the treatment of gastric cancer. Tokyo: Kanehara; 2004.

27. Uyama I, Sugioka A, Fujita J, Komori Y, Matsui H, Soga R, et al. Completely laparoscopic extragastric lymph node dissection for gastric malignancies located in the middle or lower third of the stomach. Gastric Cancer 1999;2:186-90.

28. Kitano S, Shiraishi N. Minimally invasive surgery for gastric tumors. Surg Clin N Am 2005;85:151-64.

29. Kim YW, Bae JM, Lee JH, Ryu KW, Choi IJ, Kim CG, et al. The role of hand-assisted laparoscopic distal gastrectomy for distal gastric cancer. Surg Endosc 2004;11 (in press).

30. Uyama I, Sugioka A, Fujita J, Komori Y, Matsui H, Hasumi A. Laparoscopic total gastrectomy with distal pancreatosplenectomy and D2 lymphadenectomy for advanced gastric cancer. Gastric Cancer 1999;2:230-24.

31. Uyama I, Sugioka A, Fujita J, Komori Y, Matsui H, Hasumi A. Completely laparoscopic proximal gastrectomy with jejunal interposition and lymphadenectomy. J Am Coll Surg 2000;191:1149.

32. Lacy AM, Garcia-Valdecasas JC, Delgado S, Castells A, Taura P, Pique JM, et al. Laparoscopy-assisted colectomy versus open colectomy for treatment of non-metastatic colon cancer: a randomized trial. Lancet 2002;359:2224-9.

33. The Clinical Outcomes of Surgical Therapy Study Group. A comparison of laparoscopically assisted and open colectomy for colon cancer. N Engl J Med 2004;350:2050-9.

34. Weeks JC, Nelson H, Gelber S, Sargent D, Schroeder G. Shortterm quality-of-life outcomes following laparoscopic-assisted colectomy vs open colectomy for colon cancer: a randomized trial. JAMA 2002;287:321-8.

35. Leung KL, Kwok SP, Lam SC, Lee JF, Yiu RY, Ng SS, et al. Laparoscopic resection of rectosigmoid carcinoma: prospective randomised trial. Lancet 2004:363:1187-92.

36. Janson M, Bjorholt I, Carlsson P, Haglind E, Henriksson M, Lindholm E, et al. Randomized clinical trial of the cost of open and laparoscopic surgery for colonic cancer. Br J Surg 2004;91: 409-17.

37. Volz J, Koster S, Spacek Z, Paweletz N. The influence of pneumoperitoneum used in laparoscopic surgery on an intraabdominal tumor growth. Cancer 1999;86:770-4.

38. Suematsu T, Hirabayashi Y, Shiraishi N, Adachi Y, Kitamura H, Kitano S. Morphology of the murine peritoneum after pneumoperitoneum vs laparotomy. Surg Endosc 2001;15:954-8.

39. Hirabayashi Y, Yamaguchi K, Shiraishi N, Adachi Y, Saiki I, Kitano S. Port-site metastasis after CO2 pneumoperitoneum: role of adhesion molecules and prevention with antiadhesion molecule. Surg Endosc 2004;18:1113-7.

40. Seto Y, Nagawa H, Muto Y, Kaizaki S, Kitayama J, Muto T. Preliminary report on local resection with lymphadenectomy for early gastric cancer. Br J Surg 1999;86:526-8.

41. Ohwada S, Nakamura S, Ogawa T, Izumi M, Tanahashi Y, Sato $\mathrm{Y}$, et al. Segmental gastrectomy for early cancer in the midstomach. Hepatogastroenterology 1999;46:1229-33.

42. Zhang D, Shimoyama S, Kaminishi M. Feasibility of pyloruspreserving gastrectomy with a wider scope of lymphadenectomy. Arch Surg 1998;133:993-7. 
43. Adachi Y, Inoue T, Hagino Y, Shiraishi N, Shimoda K, Kitano S. Surgical results of proximal gastrectomy for early-stage gastric cancer: jejunal interposition and gastric tube reconstruction. Gastric Cancer 1999;2:40-5.

44. Morton DL, Wen DR, Wong JH, Economou JS, Cagle LA, Storm FK, et al. Technical details of intraoperative lymphatic mapping for early stage melanoma. Arch Surg 1992;127:392-9.

45. Kitagawa Y, Fujii H, Mukai M, Kubota T, Ando N, Watanabe M, et al. The role of sentinel lymph nodes in gastrointestinal cancer. Surg Clin North Am 2000;80(6):1799-809.

46. Hiratsuka M, Miyashiro I, Ishikawa O, Furukawa H, Motomura $\mathrm{K}$, Ohigashi $\mathrm{H}$, et al. Application of sentinel node biopsy to gastric cancer surgery. Surgery 2001;129(3):335-40.

47. Yasuda S, Shimada H, Ogoshi K, Tanaka H, Kise Y, Kenmochi T, et al. Preliminary study for sentinel lymph node identification with Tc-99m tin colloid in patients with esophageal or gastric cancer. Tokai J Exp Clin Med 2001;26(1):15-8.

48. Ichikura T, Morita D, Uchida T, Okura E, Majima T, Ogawa T, et al. Sentinel node concept in gastric carcinoma. World J Surg 2002;26(3):318-22.

49. Kitagawa Y, Fujii H, Mukai M, Kubota T, Otani Y, Kitajima M. Radio-guided sentinel node detection for gastric cancer. Br J Surg 2002;89(5):604-8.

50. Carlini M, Carboni F, Petric M, Santoro R, Guadagni F, Marandino F, et al. Sentinel node in gastric cancer surgery. J Exp Clin Cancer Res 2002;21(4):469-73.

51. Hayashi H, Ochiai T, Mori M, Karube T, Suzuki T, Gunji Y, et al. Sentinel lymph node mapping for gastric cancer using a dual procedure with dye- and gamma probe-guided techniques. J Am Coll Surg 2003;196(1):68-74.

52. Miwa K, Kinami S, Taniguchi K, Fushida S, Fujimura T, Nonomura A. Mapping sentinel nodes in patients with early-stage gastric carcinoma. Br J Surg 2003;90(2):178-82.

53. Gretschel S, Bembenek A, Ulmer C, Hunerbein M, Markwardt J, Schneider U, et al. Lymphatic mapping and sentinel lymph node biopsy in gastric cancer. Chirurg 2003;74(2):132-8.

54. Yasuda S, Shimada H, Chino O, Tanaka H, Kenmochi T, Takechi $\mathrm{M}$, et al. Sentinel lymph node detection with Tc-99m tin colloids in patients with esophagogastric cancer. Jpn J Clin Oncol 2003; 33(2):68-72.

55. Tonouchi H, Mohri Y, Tanaka K, Konishi N, Ohmori Y, Kobayashi M, et al. Lymphatic mapping and sentinel node biopsy during laparoscopic gastrectomy for early cancer. Dig Surg 2003; 20(5):421-7.

56. Simsa J, Hoch J, Leffler J, Schwarz J, Pospisil R, Vajtrova R. Sentinel node biopsy in gastric cancer: preliminary results. Acta Chir Belg 2003;103(3):270-3.

57. Ryu KW, Lee JH, Kim HS, Kim YW, Choi IJ, Bae JM. Prediction of lymph nodes metastasis by sentinel node biopsy in gastric cancer. Eur J Surg Oncol 2003;29(10):895-9.
58. Song X, Wang L, Chen W, Pan T, Zhu H, Xu J, et al. Lymphatic mapping and sentinel node biopsy in gastric cancer. Am J Surg 2004;187(2):270-3.

59. Kim MC, Jung GJ, Lee JH, Choi SR, Kang do Y, Roh MS, et al. Sentinel lymph node biopsy with $99 \mathrm{mTC}$ tin-colloid in patients with gastric carcinoma. Hepatogastroenterology 2003;50 Suppl 2:214-5.

60. Nimura H, Narimiya N, Mitsumori N, Yamazaki Y, Yanaga K, Urashima M. Infrared ray electronic endoscopy combined with indocyanine green injection for detection of sentinel nodes of patients with gastric cancer. Br J Surg 2004;91(5):575-9.

61. Karube T, Ochiai T, Shimada H, Nikaidou T, Hayashi H. Detection of sentinel lymph nodes in gastric cancers based on immunohistochemical analysis of micrometastases. J Surg Oncol 2004;87 (1):32-8.

62. Kim MC, Kim HH, Jung GJ, Lee JH, Choi SR, Kang DY, et al. Lymphatic mapping and sentinel node biopsy using $99 \mathrm{mTc}$ tin colloid in gastric cancer. Ann Surg 2004;239(3):383-7.

63. Osaka H, Yashiro M, Sawada T, Katsuragi K, Hirakawa K. Is a lymph node detected by the dye-guided method a true sentinel node in gastric cancer? Clin Cancer Res 2004;10(20):6912-8.

64. Isozaki $\mathrm{H}$, Kimura $\mathrm{T}$, Tanaka $\mathrm{N}$, Satoh $\mathrm{K}$, Matsumoto $\mathrm{S}$, Ninomiya M, et al. An assessment of the feasibility of sentinel lymph node-guided surgery for gastric cancer. Gastric Cancer 2004;7:149-53.

65. Cox CE, Pendas S, Cox JM, Joseph E, Shons AR, Yeatman T, et al. Guidelines for sentinel node biopsy and lymphatic mapping of patients with breast cancer. Ann Surg 1998;227:645-53.

66. Bertagnolli M, Miedema B, Redston M, Dowell J, Niedzwiecki D, Fleshman J, et al. Sentinel node staging of resectable colon cancer. results of a multicenter study. Ann Surg 2004;240:624-8.

67. Stein HJ, Sendler A, Siewert JR. Site-dependent resection rechniques for gastric cancer. Surg Oncol Clin N Am 2002:11:405-14.

68. Kitagawa Y, Fujii H, Kumai K, Kubota T, Otani Y, Saikawa Y, et al. Recent advances in sentinel node navigation for gastric cancer: a paradigm shift of surgical management-. Seminar in Surg Oncol (in press)

69. Otani Y, Furukawa T, Kitagawa Y, Yoshida M, Saikawa Y, Kubota T, et al. New method of laparoscopy-assisted functionpreserving surgery for early gastric cancer: vagus-sparing segmental gastrectomy under sentinel node navigation. J Am Coll Surg 2004;198:1026-31.

70. Kitagawa Y, Kitajima M. Laparoscopic sentinel lymph node mapping for early gastric cancer. World J Surg (in press).

71. Matsuda J, Kitagawa Y, Fujii H, Mukai M, Dan K, Kubota T, et al. Significance of metastasis detected by molecular techniques in sentinel nodes of patients with gastrointestinal cancer. Ann Surg Oncol 2004;11:250S-4S. 